\title{
ULUSLARARASI REKLAMCILIĞI ULUSAL REKLAMCILIKTAN AYIRAN FAKTÖRLER
}

\author{
Mert UYDACI \\ M.Ü. Sosyal Bilimler M.Y.O., Öğretim Görevlisi
}

\begin{abstract}
International advertisers face many complexities not enconntered by domestic advertisers. The most basic issue concerms the degree to which global advertising should be adapted to the uniyue characteristics of various country markets. Companies vary in the degree to they adapt their advertising to local markets. In this article the differences between international advertising and national advertising have been studied for the adaptation without trouble.
\end{abstract}

\section{Gíriş}

Firmalar uluslararası pazarlara açılmaya başladıkça ürün. personel. pazarlar ve pazarlama planları ile ilgili sorunlar giderek daha önemli bir hale gelmektedir. Firma ve ajanslarm her ikisinin de diğer pazarlara başarılı bir şekilde girebilecek pazarlama stratejileri arayacak olmaları kaçınılmazdır. Alternatif ise her bir ülke için farklı bir pazarlama planı geliştirmektir.

Çok uluslu satışın parolalarından birisi de global pazarlamadır. Harvard Üniversitesi'nden Theodore Levitt'e atfedilmiş olunan bu terim. firmaların ürünleri için dünya çapında reklam ve pazarlama stratejileri geliştirebileceklerini iddia eder. Kavramın özünde ki varsayım; dünya üzerindeki bütün tüketiciler temel olarak benzerdirler ve benzer sunumlarla aralarındaki belirgin farklılıklara rağmen tepki göstereceklerdir.[1]

Global bir strateji fikri,uluslararası reklamcilara son derece çekici gelmektedir. Bu fikir tek ve koordine durumdaki bir pazarlama stratejisinin gelişsirilmesine imkan sağlayacaktır. Firmanın uluslararası pazarlama uzmanlığı. ortak kültür ve marka bilincinin koordinasyonu.uluslararası reklamcılığı firma için pratik bir seçenek haline getirmiștir. Yine de ürünün kabulü ve dağıtımındaki belli başlı farklılıklar dikkate alınmak zorundadır. Diğer yandan, reklaın: ürünün maliyetini uluslararası bir yaklaşımla büyük ölçüde azaltabilir. Uluslararası televizyon reklamları her bir ülke için tamamen yeni bir reklam hazırlanması yerine sadece ses değişiklikleriyle gerçekleştirilecektir.

Pek çok durumda. firmalar daha geniş çaplı bir pazarlama ve reklam planı geliştirmektedirler. Bu plandan yola çıkarak potansiyel pazar olarak değerlendirdikleri her bir ülkede mevcut olan özel kültürcl. ekonomik ve dil farklılıklarını göz önünde bulundurarak gerekli uyarlamaları yapmaktadırlar. Uyarlamaların çoğunda. tüketiciler bu ürünleri hangi ülke kaynaklı olduklarına bakmaksızın aldıklan bir gerçektir. Bu yüzden global pazarlamanın faydalarının çoğunun tüketicilere değil de üretici firmaların çıkarları doğrultusunda olduğudur. $\mathrm{Bu}$ yüzden yurtiçi reklamcılıkta olduğu gibi ulıslararası reklam planlarının geliştirilmesinde tüketiciye dayah pazarlama kavramı uygulanmalıdır.

Uluslararası tanıtım, firmaların uluslararası pazarlama karmasinda yer alan temel aktivitelerinden biridir. Tüketici ihtiyaçlarını karşılamak için geliştirilen ürün. fiyatlandırıldıktan ve dağıtıldıktan sonra. tüketicilerin ürünün elde edilmesi ve değeri hakkında bilgilendirilmesi gerekir. İyi tasarlanmıs bir tanıtım kampanyası. birbirini etkileyen ve aynı hedefe odaklaşılması sağlayan satış promosyonu. kişisel satış. halkla ilişkiler ve reklamdan oluşur. Uluslararası tanıtım stratejisi geliştirme beş basamaktan oluşınaktadır.

belirlemek

1- İç pazar yardımıyla tanitım karmasını belirlemek

2- Dünya çapında standardizasyon ölçüsünü

3- En etkili mesajları geliştirmek

4- Etkili medyayı seçmek

5- Dünya çapındaki pazarlama hedeflerine ulaşmak için gerekli yönetimi geliştirmek

Yabancı tüketicilerin giderek bilgilenmesi ve uluslararası rekabet reklamcılığın önemini arttırmaktadır. Çeşitli ülkelerden reklamcılar Amerikan know-how'ların satun alarak korkulur rakipler haline gelmişlerdir. Uluslararası reklamcılık en iyi.kendi ülkelerinin dışındaki ülkelerdeki kar amaçlı ve kar amaçsız organizasyonların reklamcılık aktiviteleri olarak tanımlanabilir. Uluslararası reklam dünyası, reklamcılık endịistrisine hizmet eden ve uluslararasinda fonksiyon gösteren reklam acentalarını. medyanın araşırma firmalarını. televizyon üretim merkezlerini ve birçok 
diğer firmaları içerir. Uluslararası işin içinde olan her firma. reklamcılı̆ın yerel olarak yabancı pazarlarda olduğundan oldukça farklı bir biçimde işlendiğinin farkındadır.

Dünya ticaretinin uluslararası hale gelmesiyle reklam medyası ve hizmetleri dünya çapında bir gelişme göstermiştir. Son yirmi sene içinde medya kalitesi ve ulaşımında kolaylık artmıştır. Ülkeler arası büyük farklılıklar olmasına rağmen. çok uluslu firmalar ticari medyanın çeşitlerini arttırarak reklam ajanslarının sağladıkları destek hizmetlerini hem yerel. hem de dünya çapında geliștirmişlerdir.

Reklamcıllkta en çok artıs. ülkelerdeki özel radyo ve televizyon istasyonlarının artmasıyla sağlanmıștır. Uydu yayımları ve kablolu yayın sisteminin gelişmesiyle reklamlar tüm ülkeleri kapsamıștır. Böylece kitlesel iletişim tüm dünyaya yayılmıştır.

Reklamcilık, hemen hemen tüm ülkelerde iletişim geleneklerini değiştirmektedir. Televizyon ve diğer ticari medyanın bulunmadığı ortamlarda bu medyaların yaygınlaştırılması için devamlı bir talep vardır. Kitlesel iletişimin ilerlemesi. bazı kavramların genişlemesine yol açar ve kültürel, siyasi. ekonomik entegrasyonu etkileyen ve hızlandıran en önemli etken sayılabilir.

Uluslararası reklam medyasının gelişimi, uluslararası pazarlamanın gelişmesi açısından da önemlidir. Dünyanın birçok yerinde tüketiciler ürünleri satın almak için yeterli gelire sahiptirler. ancak dünya pazarlarımın bir parçası olmadıkları için ürünle ilgili bilgilerden yoksundurlar.

\section{ULUSLARARASI REKLAMCILIĞIN STANDARTLAŞMASI VEYA ESNEK OLMASI}

Uluslararası bir reklamcı, temel reklamcılık politikalarıyla yaratıcılığına uygun bir çevre geliştirir. Reklamcilı̆ın her bir aktivitesi; merkezcil veya rnerkezcil olmayan yönetim, yerli veya yabancı reklam ajanslarının kullanımı, bütçe tahsis etme. kopyalama. medya. araştırma. geliştirıne gibi konuları kapsayan temel politikalara ihtiyaç duymaktadır.

$\mathrm{Bu}$ politikalardan en çok tartışılanı. ülkeden ülkeye farklılık gösteren reklam çeşitlendirme ölçüsüdür. Bir görüş ülkeler farklılık gösterdiği için reklamların ülkelere özgü olması gerektiğini savunmaktadır. Firmadaki yöneticiler, uygun ve etkili reklamın yapılması için her ülkeye özel ayrı bir kampanya uygulanmasinı istemektedir: Diğer bir görüş, tüm dünya pazarında standart bir reklam kampanyasını savunmaktadır. Bunun yararı: tüm pazarlarda aynı biçimde etki varatma, önemli maliyet tasarrufları ve daha iyi bir koordinasyondur.

Reklamın standart veya esnek olması coğrafyadan çok çekici modellere bağlıdır. Değişik pazarlardaki tüketiciler, benzer ürünleri farklı nedenlerle satın alyyorlarsa. reklam kampanyaları bu nedenler üzerinde yoğunlaşmalıdır. Buna karşın tüketiciler benzer uyarılara aynı tepkileri veriyorsa reklam mesajlann çeşitlendirmek anlamsızdır.

Uluslararası reklamcilikla maliyetler kontrol altında tutulur ve dünya çapındaki tanıtım programlan kolaylıkla koordine edilir. Ancak.ülkeler arası pazar farklılıkları tanıtım programlarının o ülkeye adapte edilmesini gerektirir. Çünkü uluslararası reklamcllıkta herhangi bir pozisyonun en iyisi olduğu konusunda çok az durumlar mevcuttur.

Ürün, fiziksel bir nesne olmaktan öte alıcıların beklentilerini tatmin eden bir bütündür. Ürünün tatmin etmesi ve yararlılı̆g yanısıra, kültürel değerleri ve gelenekleri de kapsar. Değişik kültürler ürünün birincil fonksiyonu karşısında aynı yararları beklerler. Örneğin, fotoğraf makinasının fotoğraf çekmesi, saatin zamanı göstermesi beklenir. Ancak. diğer özellik ve psikolojik katkıların çok büyük önemi vardır. Bir fotoğraf makinasından beklenen farklı beklentileri ele alalım. A.B.D.' de kolay bir operasyonla çekilen mükemmel resimler beklenmektedir. Almanya ve Japonya'da makine mükemmel resimler çekmelidir ancak resimlerde sanatsal bir yan bulunmalıdır. Afrika'da ise ev halkının yalnızca bir kısmı makinayı kullanıyorsa işe yaramıyor demektir. $\mathrm{Bu}$ üç pazarda da birincil fonksiyonlar olarak mükemmel resimler istenmektedir. Ancak makinadan beklenen extra yarar ve tatmin kültürden kültüre farklılık göstermektedir. Uluslararası reklamlarda temel mesaj standardize edilmekte ancak yerel duruma göre mesaja bir derece esneklik getirilmektedir. Böylece kültürel değişikliklere yer verilerek standartizasyonun ekonomik yararları arttırılmaktadır.[2]

Uluslararası veya yerel değişikliklere uyarlanmış standart reklamcılığın arasındaki tartışmalar mutlaka devam edecektir. Hangisinin uygun olacağı üründen ürüne farklılık göstermektedir. Pazarlar birbirine benzer olma yönünde hızla değişmektedir. Ancak dünya hala aynı istek ve beklentileri karşılayan homojen bir pazar olmaktan uzaktır. Bu nedenle standardizasyona engel birçok etken bulunmaktadır.

\section{ULUSAL VE ULUSLARARASI REKLAMCILIĞI FARKLI KILAN YÖNLER}

Uluslararası rekabetin ve pazarlamanın karmaşıklığının artması sonucu reklamcılardan en üst yaratıcılık seviyesi beklenmektedir. Dünyanın her yerinde reklamcılar, değişik ürünlerin benzerlikler gösterınesi ve uzmanlaşmanın artması sonucu kendi yeteneklerini geliştirmektedirler. Ancak yasa ve vergiler, kültür. medya, ürün ve maliyet sınırlamalan gibi faktörlerle ulusal ve uluslararası reklamcılık ayrılmakta 
farklılıklar yaratılmakta böylelikle yaratıcılık en ön plana çıkmaktadır.

\section{III.1. YASALAR VE VERGÍLER}

Uluslararası reklamcılığın önünü kapayan büyük engellerden birisi de bir ülkeden diğerine geçildiğinde karşılaşılan geniş düzenleme farklılıklarıdır. Bazı ülkelerin reklamlanı daha sik denetlemesi sonucu. reklamlar ülkeden ülkeye değişiklik göstermektedir. Yasalar; reklama ayrılan bütçe, kullanılan medya, reklamı yapılan ürünün cinsi,fiyatın reklama yansitılması, kopya ve telif hakları gibi konularda sınırlandırma getirebilir. Örneğin. Almanya'da reklamlarda karşılaştırmalı üstünlük kullanmak yasaktır. Başka marka bir deterjanın çamaşırları temizlemediği ileri sürülerek kendi deterjanının reklamını yapmak yasaktır. Kendi ürünlerinin en iyi olduğunu savunanlar rakiplerin yasal tehditleriyle karşı karşıya kalırlar.

Kuveyt'te devlet kontrolündeki televizyonda günde sadece otuziki dakika ve öğlenleri olmak üzere reklamlara izin verilmektedir. Reklamlarda abartılı tanımlamalar, ahlaksız kelimeler. korkulu, nefret veya öfke dolu sözler, aykırı giyim ve danslar, yarışmalar. rekabeti arttıracak nesnelerin kullanılmasi yasaktır. Sigara, kibrit, ilaç, içki,havayolları çikolata ve şeker reklamları kesinlikle yapılamaz.[3]

Hangi reklamın daha dürüst veya doğru olduğu konusundaki yorumlar ülkelere göre değişmektedir. Bir ülkede doğru kabul edilen, bir başka ülkede yasak olabilir. Yasalar ve vergiler reklamları standartizasyonu konusunda önemli bir engeldir.

\section{III.2. DIL SINIRLAMALARI}

Dil farklılıkları uluslararası reklamcılar tarafından karşılaşılan en belirgin problemndir. Dil.yanış kullanımda reklamla iletişimin etkinliğini azaltan en önemli etkenlerden biridir. Değişik ülkelerdeki değişik diller, aynı ülkedeki şive farklılıkları, konuşma ve yazma dili arasındaki nüanslar problem yaratmaktadır.

Reklamcılar biraz geç de olsa reklamların bir dilden diğerine çevrildiğinde anlamını yitirdiğini görmüşlerdir.

Reklam çoğu zaman dil içindeki nüansları kullanmaktadır. Argo ve kendine has kelime kullanımları, çevrildikleri dilde bir anlam taşımamakta ve daha da kötüsü tamamen değișik ve bazen de olumsuz anlamlara gelebilmektedir. Bu yüzden çevirmenler. etkin. belirli bir dilin, özelliklerini taşıyan çevirilerde sayısız problemle karşılaşmaktadır ve bu da iletişimi zorlaştırmaktadır. Soyutlama, kısa ve özlü yazma,az kelime kullanma gibi reklamcıların en etkili metotları çevirmenlere zorluk çıkarır. Ülke içindeki değişik kültürel kalıtım ve eğitim özelliklerine göre en basit cümle ve kavramların bile farklı yorumlanması iletişimi engeller. Gündelik kullanılan kelimeler bile farklı kültürlerde farklı anlamlara gelmektedir. [4]

Okur yazar oranı düşük ülkelerde iletişim zorlaşır ve sözlü medyanın kullanımında daha çok yaratıcılık gerekir. Bir ülkede birden fazla dilin konuşulması da ayrı bir problemdir.

\section{III.3. KÜLTÜREL FARKLILIKLAR}

Değişik kültürlerden insanlarla iletişim kurınak, reklamcılıkta yaratıcılık konusunda karşılaşılan en büyük sorunlardan biridir. Kültürel faktörlerin kişilerin algılamalarını etkilemeleri nedeniyle iletişim kurmak daha zordur. Bir toplum içinde farklı algılamalar mevcutsa. her bir algilama grubuna verilecek mesaj da farklı olmalıdır.

Reklam sadece ürünler hakkında bilgi taşınaz. Aynı zamanda bir ülkenin değerlerini ve kültürel standartlarını da iletir. Uluslararası reklamcilar belirlenmesi en zor olan değerin bir ülkenin kültürel yapısı olduğunu ve bunun da ürün tanıtımının başarısı için hayati öneme sahip bulunduğunu bilmektedirler

Kültürel farklılıkların bilinmesi,reklamın başarıya ulaşmasını sağlar. Uluslararası reklamcılar kültürel adaptasyonları gerçekleştirmeye aşlamışlardır. Reklamciların bilmesi gereken en önemli konulardan da biri renklerin farklı kültürlerde değişik anlamları sembolize ettikleridir. Beyaz;Avrupa'da saflık anlamına gelmekte iken, Asya'da ölümle özdeşleşmektedir. Ayrıca uzman bir reklamcı, batıda siyahın ve doğuda beyazın otomatik olarak ölüımü çağnıștırdığını bilmelidir. Renk; iletişimde küçük bir ayrıntıdır, ancak her kültürdeki anlamı bilinirse doğru rengin seçimi kolaylaşır.

Gelenekler nedeniyle ortaya çıkan farklı algılamalar. aşılması zor bir konudur. Hong Kong'daki pazar araştırmalarına göre peynir yabancılar tarafindan kabul edilmekte. Çinliler tarafindan ise reddedilmektedir. Çinlilere göre vücut sıcaklığı çok önemlidir. Sıcak süt sıcaklık verirken. ılık süt soğukluk verir. Brandy desteklendiği halde. viski zararlı kabul edilmektedir.

A.B.D.' de bir erkeğin kadın vücuduna dokunduğu bir sabun reklamı Japonya'da kabul görmez. Çünkü bir erkeğin kadınla aynı banyoda olması tabudur.[5]

Reklamcilar, ülkelerarası kültür farklılıklarıyla uğraştıkları yetmezmiş gibi bir de aynı kültür içindeki farklılıkları gözönüne almak zorundadır. Örneğin: Hong Kong'da on çeşit kahvaltı alışkanlığı mevcuttur. Gençler yaşlilardan. taşralılar : şehirlilerden farklılıklar göstermektedir. Bunun yanında geleneklerin değișmesi gibi problemlèr vardır. Çoğu ülkede, insanlar alışkanlıklarına bağlıdır, ancak davranışlarında bazı değişiklikler yapmaya isteklidirler. Birkaç yıl öncesine 
kadar Japonya'da neskafenin pazarlanması imkansız. olduğu halde.şimdi gençlerin favori içeceği haline gelmiştir. Böylelikle kendilerini Avrupalı hissetmektedirler. Kahve içme alışkanlığı Japonya'da hazır kahve ile kazandırılmıştır.ancak başka bir kahve ürünü için pazar bulunmamaktadır.

\section{III.4. MEDYA SINIRLAMALARI}

Medya ile yaratılıcılığa sųurlamalar getirilebilir ve pazarlamacılar diğer pazarlama karması elemanlarını kullanmaya zorlanabilir. Hemen hemen her ülkede aymı çeşit medyalar bulunmasına karşın,ülkeden ülkeye farklılık gösteren bazı özel durumlar ve problemler olabilir. Uluslararası reklamcılıkta dikkate almması gereken ana faktörler: kolay ulaşılabilirlik. maliyet ve kullamılacak medyanın tipidir.

Bölgesel farklılıklar ve pazarla ilgili veri eksikliği nedeniyle bu faktörlere daha fazla önem vermek gerekebilir. Reklam kuşağındaki reklam sayısının çokluğu.ülkedeki medya sayısının fazlalı̆̆ı. medyaların pazarın sadece belli bölümlerine hitap etmeleri ve reklam çizelgelerinin önceden belirlendiği durumlarda rcklamciların tüm yeteneklerini sergilemeleri gerekınektedir.

Çoğu ülkede kullanılan medyanın fiyatları pazarlığa açıktır. Medya maliyetlerini düşürmek için reklam ajansları tarafindan indirimler yapılabilir. Müşteriyle iletişim kurmanın maliyeti ülkeden ülkeve farklılık göslermektedir. Bazı pazarlarda ise reklam sürelerinin kısa olması nedeniyle fiyatlar daha yüksek hizla artmaktadır.

Uluslararası reklamcılıkta en önemli zıtlıklardan biri. bazı ülkelerdeki medya çeşidinin çok. bazılarında ise az olmasıdır. Bazı ülkelerde kullanılan reklam malzemeleri nedeniyle bazı medyalar devlet tarafindan yasaklanmıştır. Bu durum daha çok radyo ve TV' de gözlenir. Çoğu ülkede. teklif edilen reklamların hepsini yayımlayan çok az dergi ve gazete vardır. Bunun tersi olarak. bazı ülkelerdeki gazete sayısı. reklamcının hepsinin maliỵetini karşılayamayacağı kadar çoktur.

Maliyet nedeniyle ortaya medyayı takip etme problemi çıkmaktadır. Burada iki zorluk mevcuttur. İlki reklâmla halkın bazı kesimlerine ulaşılamaması. ikincisi ise takip oranı hakkındaki bilgi yetersizliğidir. Birçok pazarda tüketicilere ulaşınak için birkaç medya birden kullanılmaktadır. $\mathrm{Bu}$ ülkelerin bazılarmnda, medya nedeniyle pazar ekonomik olmayan dilimlere böllïnmüștür. Tirajın belirlenmesi ise ayrı bir zorluktur. Birçok ülkede denetim büroları olmasına karşın doğru bir tiraja ve okuyucuyla ilgili bilgilere ulaşmak guiçı̈̈r. Gazete tirajları çok abarılıdır aymı zamanda radyo ve TV izlleyicilerini ölçmek çok zordur. ancak en azından coğrafi olarak belirlenebilmektedir.|6|
Ulaşılan tüketicilerin sayısı bilinse bile, bu pazarın yapısı hakkında bir takım kuşkular olabilir. Uluslararası pazarlamada en çok zorlanılan konulardan birisi de. pazarla ilgili veri elde etmektir. Gelir. yaş. coğrafi dağılım gibi en temel veriler bile kolay elde edilemeyebilir. Doğru pazar verilerine ulaşılabilinirse. değișik medyalar ile ulaşılan tüketici farklılıkları ve ülkeler arası farklılıklar kolayca anlaşılabilir. Ufak bir ülkede bile. sınırları içinde birçok alt kültür mevcut olabilir. Reklam ajansının hedefi. tüm pazarı kapsayacak bir medyayı seçmektir.

\section{III.5. ÜRETIM VE MALIYYT SINIRLAMALARI}

Bütçenin gereksiz olduğı veya kötü baskı, kötü kalitcli kağıt gibi üretim sınırlamalarının bulunduğu durumlarda yaratıcılık ayrı bir önem kazanır. Küçük pazarlardaki düşük maliyetlerle üretim yapma zorunluluğu başka sorunlara da yol açar. Örneğin: reklam panolarıyla elde edilecek gelir büyük afişlerin üretimini karşılamıyorsa, el afişleri kullanılacaktır. Bazı durumlarda ise bir ülkede hedeflenen pazarın hepsine ulaşabilmek amacıyla.birden fazla dil kullanılabilir. Bu durumda reklam birden fazla dilde yaymmlanmak zorundadır. Buda maliyet ve üretim sinırlamaları demektir.

\section{IV-SONUC}

Uluslararası reklamcilıkta akla gelen ilk soru "Reklamı hangi dereceye kadar bir ülkeden diğerine adaptc etmek durumundayı" olacaktır. Reklamcılıktaki bu farklılıklar dünya çapındaki standart reklam kampanyaları için büyük engeldir. Hedef pazara bir mesaj verirken. birçok ülkede etkin iletişim kurulabiliyorsa reklamlar standart hale getirilir yoksa yerel özelliklere göre uyarlanır. Satışları arttıran reklamın standart olması veya çeşitlilik göstermesi değil, pazarm mesajı doğru algılayabilmesidir.

\section{KAYNAKLAR}

[1] LLVITT Theodore, "Globalizations Of Markets", Global Marketing Prespectives, Edit By Jagdish Sheth ve Abdolreza Eshghi, South-Western Publishing Co., 1st Edition, 1989

[2] DUNN S.Watson BARTON M.Anold KRUGMAN M.Dean REID N.Leonard, Advertising, The Dryden Press, 7th Edition, 1990

[3] KlE:GAN J.Warren, Global Marketing Management, Prentice Hall, 4th Edition, 1989

[4] COTTOORA R.Philip, International Marketing, Irwin Inc., 6th Edition, 1987

[5] RUSSSELL Thomas Ronald W., Kleppner's Advertising Prodecure, Prentice Hall, 4th Edition, 1993

[6] KOTLER P ARMSTRONG G., Marketing An Introduction, Prentice Hall International .3rd Edition, 1993. 